\title{
Exploring the Outcomes of Portal Vein Thrombosis in the Clinical Setting of Cirrhosis, Malignancy, and Intra-abdominal Infections with and without Anticoagulation: A Retrospective 5-Year Study
}

\author{
Ashish Anil Sule, MD, MRCP, FAMS, FRCP, FICA ${ }^{1} \quad$ Joanne B. Joseph ${ }^{1}$ Samuel C. J. Chew ${ }^{1}$ \\ Julie George, MRCP, FAMS ${ }^{1}$ Tay Jam Chin, FAMS, FRCP ${ }^{1}$ \\ ${ }^{1}$ Department of General Medicine, Tan Tock Seng Hospital, Singapore \\ Int J Angiol 2018;27:208-212. \\ Address for correspondence Ashish Anil Sule, MD, MRCP, FAMS, FRCP, \\ FICA, Department of General Medicine and Vascular Medicine, Tan \\ Tock Seng Hospital, 11 Jalan Tan Tock Seng, Singapore 308433 \\ (e-mail: ashishsule@yahoo.com).
}

\section{Abstract \\ Keywords \\ - thrombophilia \\ - portal vein thrombosis \\ - anticoagulation \\ - low molecular weight heparin}

The aim of this study was to understand the differences in clinical outcomes in portal vein thrombosis (PVT) patients with cirrhosis, malignancy, and abdominal infections, with or without anticoagulation. This study was approved by ethics committee. Data were collected from 2011 to 2016. Patients were classified into three groups: PVT with cirrhosis, malignancy, and infections. Primary outcomes measures collected were clot resolution, bleeding, recurrence, and death. Frequency, means, and percentages were calculated. In total, 30 patients were analyzed in this study. Mean age was 60.8 years (range of 30-91 years). There were 19 (63.3\%) males and 11 (36.7\%) females with ethnicity: 21 (70.0\%) Chinese, 2 (6.7\%) Malay, 2 (6.7\%) Indian, and $5(16.7 \%)$ other race. Fifteen patients received anticoagulation and 15 did not receive anticoagulation. Of the 15 patients who received anticoagulation, there was complete resolution of thrombus in 5 (33.3\%), partial resolution in 1 (6.7\%), and no resolution in $9(60.0 \%)$. Of these 15 patients, there was bleeding in $3(20.0 \%)$, there was no recurrence in 9 (60.0\%), and $3(20.0 \%)$ died during the period of follow-up. Of the 15 patients who did not receive anticoagulation, there was complete resolution of thrombus in 2 (13.3\%), partial resolution in $0(0.0 \%)$, and no resolution in $13(86.7 \%)$. Of these 15 patients, there was bleeding in $0(0 \%)$, there was recurrence in $2(13.3 \%)$, and $6(40.0 \%)$ died during the period of follow-up. Anticoagulation is effective in PVT. It reduces mortality with lower rate of recurrence. However, it is associated with increased risk of bleeding.
Portal vein thrombosis (PVT) is a potentially life-threatening aliment stems from multiple factors, both local and systemic prothrombotic risk factors. ${ }^{1}$ Patients may present asymptomatically or within life-threatening intestinal infarction. Conditions including cirrhosis, malignancy, and abdominal infections may precipitate thrombus formation, and lead to complications of intestinal ischemia, portal cholangiopathy, portal hypertension, and death. ${ }^{2}$
The use of anticoagulants in PVT poses a risk to patients with any aliment because of increased risk of gastrointestinal bleeding with portal hypertension. ${ }^{3}$ Current guidelines are unclear on the efficacy of anticoagulant therapy in patients with PVT. ${ }^{4,5}$ Exploring the outcomes of all three groups of patients with and without the use of anticoagulants will highlight the possible effectiveness and safety of this treatment, helping guide treatment in the future. published online

October 4, 2017
Copyright $\odot 2018$ by Thieme Medical Publishers, Inc., 333 Seventh Avenue, New York, NY 10001, USA. Tel: +1(212) 584-4662. ISSN 1061-1711. 


\section{Aim}

The aim of this study was to understand the differences in clinical outcomes in PVT patients with cirrhosis, malignancy, and abdominal infections, with or without anticoagulation.

\section{Method}

This study was approved by ethics committee (Domain Specific Review Board, Singapore). Data were collected from inpatient referrals to the Department of Vascular Medicine, General Medicine, Tan Tock Seng Hospital, for PVT, from 2011 to 2016.

Patients were classified into three groups:

1. PVT with cirrhosis

2. PVT patients with primary or secondary liver malignancy

3. PVT patients with intra-abdominal infections

Patients excluded were those with missing data for primary outcome measures or those with overlap of PVT for two or more conditions. Demographic data along with various comorbidities including diabetes, hypertension, previous thrombotic events, and hypercoagulable states were collected. Data were also collected for extent of PVT occlusion and additional vein occlusions. Primary outcomes measures collected were clot resolution, bleeding, recurrence, death in all three groups, and overall with or without anticoagulation.

Frequency, means, and percentages were calculated and the data across each subgroup were compared with the variables of use of anticoagulant therapy compared with those who did not receive.

\section{Results}

Data were analyzed for 36 patients. Four patients were lost to follow-up, two patients were excluded as they had both cirrhosis and intra-abdominal infections, and it was difficult to classify them. In total, 30 patients were analyzed in this study.

Mean age was 60.8 years (range of 30-91 years). There were $19(63.3 \%)$ males and 11 (36.7\%) females with ethnicity: 21 (70.0\%) Chinese, 2 (6.7\%) Malay, 2 (6.7\%) Indian, and 5 (16.7\%) other race. Patients developing PVT from malignancy in this group were 13 (43.4\%), 13 (43.4\%) with infections, and 4 (13.3\%) with cirrhosis. Out of 30 patients overall, 15 received anticoagulation and 15 did not receive anticoagulation. The data on demographic, comorbidities, investigations, complications, and outcomes are summarized in - Table 1.

Comparing the subgroups of those who received anticoagulation to those who did not receive anticoagulation, mean age was 55.6 years compared with 66 years. The group of 15 who received anticoagulation therapy had a higher proportion of intra-abdominal infection. In PVT group of 15 patients who did not receive anticoagulation, malignancy was most common cause, either from primary hepatocellular carcinoma or hepatocellular carcinoma with metastasis ( $\sim$ Table $\mathbf{1})$.

The group who received anticoagulation had a lower proportion of patients with hypertension and history of
Table 1 Demographic data

\begin{tabular}{|c|c|c|c|}
\hline & Overall & Anticoagulation & $\begin{array}{l}\text { No } \\
\text { anticoagulation }\end{array}$ \\
\hline Count & 30 & $\begin{array}{l}15 \\
(50.0 \%)\end{array}$ & $\begin{array}{l}15 \\
(50.0 \%)\end{array}$ \\
\hline $\begin{array}{l}\text { Age: mean } \\
(\mathrm{y})\end{array}$ & 60.8 & 55.6 & 66.0 \\
\hline $\begin{array}{l}\text { Range } \\
(\mathrm{y})\end{array}$ & $30-91$ & $30-77$ & $45-91$ \\
\hline \multicolumn{4}{|l|}{ Gender } \\
\hline Male & $\begin{array}{l}19 \\
(63.3 \%)\end{array}$ & $\begin{array}{l}11 \\
(86.7 \%)\end{array}$ & $\begin{array}{l}8 \\
(53.3 \%)\end{array}$ \\
\hline Female & $\begin{array}{l}11 \\
(36.7 \%)\end{array}$ & $\begin{array}{l}4 \\
(26.7 \%)\end{array}$ & $\begin{array}{l}7 \\
(46.7 \%)\end{array}$ \\
\hline \multicolumn{4}{|l|}{ Ethnicity } \\
\hline Chinese & $\begin{array}{l}21 \\
(70.0 \%)\end{array}$ & $\begin{array}{l}10 \\
(66 / 7 \%)\end{array}$ & $\begin{array}{l}11 \\
(73.3 \%)\end{array}$ \\
\hline Malay & $\begin{array}{l}2 \\
(6.7 \%)\end{array}$ & $\begin{array}{l}0 \\
(0.0 \%)\end{array}$ & $\begin{array}{l}2 \\
(13.3 \%)\end{array}$ \\
\hline Indian & $\begin{array}{l}2 \\
(6.7 \%)\end{array}$ & $\begin{array}{l}1 \\
(6.7 \%)\end{array}$ & $\begin{array}{l}1 \\
(6.7 \%)\end{array}$ \\
\hline Others & $\begin{array}{l}5 \\
(16.7 \%)\end{array}$ & $\begin{array}{l}4 \\
(26.7 \%)\end{array}$ & $\begin{array}{l}1 \\
(6.7 \%)\end{array}$ \\
\hline Malignancy & $\begin{array}{l}13 \\
(43.4 \%)\end{array}$ & $\begin{array}{l}6 \\
(40.0 \%)\end{array}$ & $\begin{array}{l}7 \\
(46.7 \%)\end{array}$ \\
\hline Infection & $\begin{array}{l}13 \\
(43.4 \%)\end{array}$ & $\begin{array}{l}8 \\
(53.3 \%) \\
\end{array}$ & $\begin{array}{l}5 \\
(33.3 \%)\end{array}$ \\
\hline Cirrhosis & $\begin{array}{l}4 \\
(13.3 \%)\end{array}$ & $\begin{array}{l}2 \\
(13.3 \%)\end{array}$ & $\begin{array}{l}2 \\
(13.3 \%)\end{array}$ \\
\hline \multicolumn{4}{|l|}{ Comorbidities } \\
\hline $\begin{array}{l}\text { Diabetes } \\
\text { mellitus }\end{array}$ & $\begin{array}{l}8 \\
(26.7 \%)\end{array}$ & 4 & 4 \\
\hline Hypertension & $\begin{array}{l}14 \\
(46.7 \%)\end{array}$ & 9 & 5 \\
\hline $\begin{array}{l}\text { Previous } \\
\text { thrombotic } \\
\text { events }\end{array}$ & $\begin{array}{l}4 \\
(13.3 \%)\end{array}$ & 3 & 1 \\
\hline $\begin{array}{l}\text { Hypercoagulable } \\
\text { state }\end{array}$ & $\begin{array}{l}5 \\
(16.7 \%)\end{array}$ & 2 & 3 \\
\hline
\end{tabular}

previous thrombotic events compared with those who did not receive anticoagulation. Incidence of diabetes was the same in both groups (-Table $\mathbf{1}$ ).

Investigations of PVT occlusion extent, presence of intestinal ischemia, portal hypertension, portal cholangiopathy, and thrombocytopenia were performed prior to initiation of treatment. Out of 15 patients in both arms (anticoagulation vs. no anticoagulation), complete luminal occlusion was seen in 10 out of 15 patients in each group and partial occlusion was seen in 5 out of 15 patients in each group. Involvement of other veins such as superior mesenteric, inferior mesenteric, or splenic vein is shown in - Table 2. Single case of intestinal ischemia was seen in patient who did not receive anticoagulation. Incidence of portal hypertension was seen in two patients in anticoagulation group and one patient in the other group.

Of the 15 patients who received anticoagulation, there was complete resolution of thrombus in 5 (33.3\%), partial 
Table 2 Investigations and complications: overall

\begin{tabular}{|c|c|c|c|}
\hline & Overall & Anticoagulation & No anticoagulation \\
\hline Total & 30 & $15(50.0 \%)$ & $15(50.0 \%)$ \\
\hline \multicolumn{4}{|l|}{ Radiology scan } \\
\hline PVT occlusion: complete & $20(66.7 \%)$ & $10(66.7 \%)$ & $10(66.7 \%)$ \\
\hline PVT occlusion: partial & $10(33.3 \%)$ & $5(33.3 \%)$ & $5(33.3 \%)$ \\
\hline Additional occlusion: 1 vein (SMV, IMV, SV) & 8 & 5 & 3 \\
\hline Additional occlusion: 2 veins (SMV, IMV, SV) & 7 & 4 & 3 \\
\hline Additional occlusion: 3 veins (SMV, IMV, SV) & 2 & 2 & 0 \\
\hline Intestinal ischemia & 1 & 0 & 1 \\
\hline Portal hypertension & 3 & 2 & 1 \\
\hline Portal cholangiopathy & 0 & 0 & 0 \\
\hline Thrombocytopenia (platelet $<100$ ) & 7 & 4 & 3 \\
\hline
\end{tabular}

Abbreviations: IMV, inferior mesenteric vein; SMV, superior mesenteric vein; SV, splenic vein.

resolution in $1(6.7 \%)$, and no resolution in $9(60.0 \%)$. Of these 15 patients, there was bleeding in $3(20.0 \%)$, there was no recurrence in $9(60.0 \%)$, and $3(20.0 \%)$ died during the period of follow-up. Of the 15 patients who did not receive anticoagulation, there was complete resolution of thrombus in 2 (13.3\%), partial resolution in $0(0.0 \%)$, and no resolution in 13 (86.7\%). Of these 15 patients, there was bleeding in $0(0 \%)$, there was recurrence in 2 (13.3\%), and 6 (40.0\%) died during the period of follow-up.

Out of the 13 patients with malignancy, 6 patients received anticoagulation and 7 patients did not receive anticoagulation, the mortality rate was 4 (66.7\%) out of 6 in anticoagulation group and 4 (57.1\%) out of 7 in group who did not receive anticoagulation. However, the survival time in days (mean) was 291 days (range of 22-981) in anticoagulation group and 90 days (range of 6-219) in group who did not receive anticoagulation. Out of the 13 patients with infections, 8 patients received anticoagulation and 5 patients did not receive anticoagulation. There was no mortality rate in any groups; however, there was recurrence in one out of five patients in group who did not receive anticoagulation and no recurrence in the group who received anticoagulation. Out of the four patients with infections, two patients received anticoagulation and two patients did not receive anticoagulation. There was no mortality rate in anticoagulation group compared with $50 \%$ mortality in the group which did not receive anticoagulation. There was recurrence in one out of two patients in patient who did not receive anticoagulation.

Anticoagulation therapies of low-molecular-weight heparin (LMWH) or a combination of LMWH and warfarin were used during the 5-year period. Of the 15 patients who received anticoagulation, 7 (46.7\%) received $\mathrm{LMWH}$, and 8 (53.3\%) received the combination of $\mathrm{LMWH}$ and warfarin. Mean target international normalized ratio (INR) in patients receiving warfarin was 1.67 , with a range of 1 to 3.3. Only three of the eight patients were within this target INR for a period of $60 \%$ or more. Mean duration of anticoagulation use was 66 days, with a range of 2 to 243 days (-Table 3 ).

Table 3 Use of anticoagulation

\begin{tabular}{|l|l|l|l|l|}
\hline & Overall & Malignancy & Infection & Cirrhosis \\
\hline Overall & 15 & 6 & 9 & 3 \\
\hline Regime: LMWH & $7(46.7 \%)$ & $5(83.3 \%)$ & $4(44.4 \%)$ & $1(33.3 \%)$ \\
\hline Regime: LMWH + warfarin & $8(53.3 \%)$ & $1(16.7 \%)$ & $5(55.6 \%)$ & $2(66.7 \%)$ \\
\hline Target INR: mean & 1.67 & 2.65 & 1.52 & 2.21 \\
\hline Target INR: range & $1-3.3$ & $1.99-3.31^{\text {a }}$ & $1-2.06$ & $2.01-2.4$ \\
\hline INR within therapeutic range 60\% of the time & 3 & 0 & 2 & 3 \\
\hline Anticoagulation duration: mean duration (d) & 66 & 75 & 61 & $2-243$ \\
\hline Anticoagulation duration: range (d) & $2-243$ & $11-122$ & $10-45$ \\
\hline
\end{tabular}

Abbreviations: INR, international normalized ratio; LMWH, low-molecular-weight heparin.

${ }^{a}$ Difficult to titrate due to hepatocellular carcinoma.

Note: LMWH or a combination of LMWH and warfarin was used in patients. No novel anticoagulation agents, such as rivaroxaban or dabigatran, were used. Target INR for patients on LMWH and warfarin therapy recorded. 


\section{Discussion}

The efficacy of anticoagulant therapy in the setting of PVT has been well documented in the previous studies. In a 2015 meta-analysis of 16 observational studies on cirrhotic patients with PVT, Qi et al determined a pool rate, the rates of recanalization with anticoagulation, was significantly higher in the anticoagulated group than in the nonanticoagulated group (odds ratio $=4.16,95 \%$ confidence interval $[\mathrm{CI}]$ $=1.88-9.20, p=0.0004) .{ }^{5}$ Our data suggest similar results.

Increased mortality rates were identified in PVT patients with cirrhosis. ${ }^{6}$ A study by Turnes et al suggests a rate of $87 \%$ for 5 -year survival of patients receiving anticoagulation therapy. ${ }^{7}$ From our data, mortality rates were lower in PVT patients who received anticoagulation. Mean survival duration was increased from 90 to 291 days from use of anticoagulants in patients with PVT and malignancy.

Increased age in PVT is also known to be associated with increased mortality-with a hazard ratio of $1.02(95 \% \mathrm{CI}){ }^{6}$ In our study group, patients who received anticoagulation were 10.4 years younger compared with those who did not receive anticoagulation. This may account for decreased mortality rates seen in patients on anticoagulation in our study. The effects of thrombus extent have been described in the previous study. Greater the extent, poorer the outcomes. ${ }^{8}$ In our study, the complete and partial occlusions were similar in both groups.

In a study by Condat et al, 84 of 136 patients were treated with anticoagulant therapy, a documented incidence rate of gastrointestinal bleeding was recorded as 12.5 per 100 patient-years $(95 \% \mathrm{CI}, 10-15){ }^{3}$ The study concluded by stating that the risk of thrombosis is currently as clinically significant as the risk of bleeding-with the benefit-risk ratio favoring the use of anticoagulant therapy. In our study, there was increase bleeding risk of patients receiving anticoagulation.

A decrease in recurrence and complete thrombosis and increase in recanalization rates are seen with the use of anticoagulation..$^{9-11}$ Similar findings were seen with our study.

The use of anticoagulation in noncirrhotic patients with acute PVT, anticoagulation therapy is beneficial. ${ }^{12-16}$ Thrombolysis has also been used in extensive mesenteric vein and PVT. ${ }^{13}$ In our study, no patients received thrombolysis. It is also known that use of anticoagulation therapy to treat PVT in the setting of cirrhosis should be done after a thorough assessment of the risk of bleeding against the risk of rethrombosis. ${ }^{17}$

All patients with PVT should be investigated for thrombophilic conditions as possible causes. Cirrhosis is considered as the main cause of PVT and is a fluctuant disease. Treatment with low-weight heparin should be considered in these patients. ${ }^{18}$ Investigating for thrombophilia is not a routine practice in our center.

Anticoagulants are a safe treatment for PVT and partial or complete recanalization is seen in many patients. ${ }^{19}$ In our study, anticoagulation increased the bleeding risk by $20 \%$. The early initiation of anticoagulation in patients of superior mesenteric vein thrombosis combined with PVT could minimize the serious complication such as peritonitis due to bowel necrosis required immediate exploratory laparotomy. ${ }^{20}$ Our understanding of the etiology, natural history, and treatment options for extrahepatic PVT have improved over the past few years. The recognition that multiple risk factors, including inherited and acquired thrombophilic predispositions, are involved in the majority of cases merits a methodical search for these, as their identification may influence management. ${ }^{21}$ Rare case of massive upper gastrointestinal bleeding due to pancreatic pseudocyst rupture into the duodenum, which developed during anticoagulation therapy for acute pancreatitis associated with PVT has been reported. ${ }^{22}$ Thus, bleeding risk on anticoagulation needs to be monitored closely in these patients.

Our study shows that over 5-year period, treatment of PVT with anticoagulation irrespective of cause, there is a benefit in anticoagulation therapy though there is slight increase in bleeding risk in these patients with overall improvement in mortality.

However, the study has the following limitations:

1. This is retrospective data analysis.

2. The sample size is small. This is due to the fact that PVT is not very common condition seen in our population.

\section{Conclusion}

Anticoagulation is effective in PVT. It reduces mortality by $50 \%$, helps in resolution of thrombus, and lower rate of recurrence when compared with those with no anticoagulation. The rate of recanalization with anticoagulation is three times higher compared with ones who do not receive anticoagulation. However, anticoagulation is associated with three times increased risk of bleeding and should be used with caution in patients with increased bleeding risk.

\section{References}

1 Amitrano L, Guardascione MA, Brancaccio V, et al. Risk factors and clinical presentation of portal vein thrombosis in patients with liver cirrhosis. J Hepatol 2004;40(05):736-741

2 Parikh S, Shah R, Kapoor P. Portal vein thrombosis. Am J Med 2010;123(02):111-119

3 Condat B, Pessione F, Hillaire S, et al. Current outcome of portal vein thrombosis in adults: risk and benefit of anticoagulant therapy. Gastroenterology 2001;120(02):490-497

4 Sule A, Borja A, Chin TJ. Progression of thrombus in portal vein, superior mesenteric vein, and splenic vein even on anticoagulation in a patient with ascending colonic malignancy with liver metastasis: portal vein thrombosis versus portal vein tumor thrombosis. Int J Angiol 2016;25(05):e97-e99

5 Qi X, De Stefano V, Li H, Dai J, Guo X, Fan D. Anticoagulation for the treatment of portal vein thrombosis in liver cirrhosis: a systematic review and meta-analysis of observational studies. Eur J Intern Med 2015;26(01):23-29

6 Englesbe MJ, Kubus J, Muhammad W, et al. Portal vein thrombosis and survival in patients with cirrhosis. Liver Transpl 2010;16(01): 83-90

7 Turnes J, García-Pagán JC, González M, et al. Portal hypertensionrelated complications after acute portal vein thrombosis: impact of early anticoagulation. Clin Gastroenterol Hepatol 2008;6(12): 1412-1417

8 Condat B, Pessione F, Helene Denninger M, Hillaire S, Valla D. Recent portal or mesenteric venous thrombosis: increased 
recognition and frequent recanalization on anticoagulant therapy. Hepatology 2000;32(03):466-470

9 Huard G, Bilodeau M. Management of anticoagulation for portal vein thrombosis in individuals with cirrhosis: a systematic review. Int J Hepatol 2012;2012:672986

10 Amitrano L, Guardascione MA, Menchise A, et al. Safety and efficacy of anticoagulation therapy with low molecular weight heparin for portal vein thrombosis in patients with liver cirrhosis. J Clin Gastroenterol 2010;44(06):448-451

11 Villa E, Cammà C, Marietta M, et al. Enoxaparin prevents portal vein thrombosis and liver decompensation in patients with advanced cirrhosis. Gastroenterology 2012;143(05):1253-60. e1, 4

12 Plessier A, Darwish-Murad S, Hernandez-Guerra M, et al; European Network for Vascular Disorders of the Liver (EN-Vie). Acute portal vein thrombosis unrelated to cirrhosis: a prospective multicenter follow-up study. Hepatology 2010;51(01):210-218

13 Tateishi A, Mitsui H, Oki T, et al. Extensive mesenteric vein and portal vein thrombosis successfully treated by thrombolysis and anticoagulation. J Gastroenterol Hepatol 2001;16(12):1429-1433

14 Hall TC, Garcea G, Metcalfe M, Bilku D, Dennison AR. Management of acute non-cirrhotic and non-malignant portal vein thrombosis: a systematic review. World J Surg 2011;35(11):2510-2520
15 Sheen CL, Lamparelli H, Milne A, Green I, Ramage JK. Clinical features, diagnosis and outcome of acute portal vein thrombosis. QJM 2000;93(08):531-534

16 Kocher G, Himmelmann A. Portal vein thrombosis (PVT): a study of 20 non-cirrhotic cases. Swiss Med Wkly 2005;135(2526):372-376

17 Tsochatzis EA, Senzolo M, Germani G, Gatt A, Burroughs AK. Systematic review: portal vein thrombosis in cirrhosis. Aliment Pharmacol Ther 2010;31(03):366-374

18 Manzano-Robleda MdelC, Barranco-Fragoso B, Uribe M, MéndezSánchez N. Portal vein thrombosis: what is new? Ann Hepatol 2015;14(01):20-27

19 Kinjo N, Kawanaka H, Akahoshi T, et al. Portal vein thrombosis in liver cirrhosis. World J Hepatol 2014;6(02):64-71

20 Joh JH, Kim DI. Mesenteric and portal vein thrombosis: treated with early initiation of anticoagulation. Eur J Vasc Endovasc Surg 2005;29(02):204-208

21 Webster GJM, Burroughs AK, Riordan SM. Review article: portal vein thrombosis - new insights into aetiology and management. Aliment Pharmacol Ther 2005;21(01):1-9

22 Park WS, Kim HI, Jeon BJ, Kim SH, Lee SO. Should anticoagulants be administered for portal vein thrombosis associated with acute pancreatitis? World J Gastroenterol 2012;18(42):6168-6171 